\title{
ÓBITO DO PACIENTE INTENSIVO NA RECUPERAÇÃO PÓS-ANESTÉSICA: UMA EXPERIÊNCIA DESCONTEXTUALIZADA
}

\section{Death of intensive care patient in the post-anesthesia care unit: a decontextualized experience} Óbito del paciente intensivo en la recuperación pos-anestésica: una experiencia descontextualizada

\author{
Lisiane Vidal Lopes Machado', Dulcilene Pereira Jardim²*
}

RESUMO: Objetivos: Identificar e caracterizar o perfil de pacientes intensivos que evoluíram a óbito durante sua permanência na recuperação pós-anestésica (RPA) e elencar as dificuldades enfrentadas pela equipe de enfermagem. Método: Trata-se de um estudo retrospectivo, tendo como fonte de informação os prontuários e os livros de registros da RPA de cinco anos (de julho de 2012 a julho de 2017), em um hospital público do Rio Grande do Sul. Resultados: Durante o período estudado, 30 pacientes intensivos foram a óbito na RPA, sendo a maior parte do sexo masculino, com idade média de 50,97 anos, que permaneceram no leito, em média, por 14,8 horas, pertencentes à especialidade de neurocirurgia, sendo a causa de óbito mais frequente a parada cardiorrespiratória. Conclusão: A admissão de pacientes intensivos na RPA requer a adequação da unidade em sua estrutura física e operacional, com uma equipe adequada em número e capacitação técnica para garantir uma assistência segura e humanizada aos pacientes intensivos, bem como aos demais pacientes em pós-operatório. Palavras-chave: Sala de recuperação. Período de recuperação da anestesia. Enfermagem em sala de recuperação. Enfermagem perioperatória. Cuidados intensivos.

ABSTRACT: Objectives: To identify and characterize the profile of intensive care patients who progressed to death during their stay in the post-anesthesia care unit (PACU), and list the difficulties faced by the nursing staff. Method: This is a retrospective study that uses the medical records and PACU record books of five years (from July of 2012 to July of 2017) from a public hospital in Rio Grande do Sul as information source. Results: In the period under study, 30 intensive care patients died in the PACU, most of them male, with a mean age of 50.97 years, who remained in bed, on average, for 14.8 hours, and belonged to the neurosurgery specialty. The most frequent cause of death was cardiorespiratory arrest. Conclusion: The admission of intensive care patients in the PACU requires adjustments in the physical and operational structure of the unit, staff in sufficient numbers and with appropriate technical training to ensure safe and humanized assistance to intensive care patients, as well as other patients in the postoperative period.

Keywords: Recovery room. Anesthesia recovery period. Postanesthesia nursing. Perioperative nursing. Critical care.

RESUMEN: Objetivos: Identificar y caracterizar el perfil de pacientes intensivos que evolucionaron a óbito durante su permanencia en la recuperación pos-anestésica (RPA) y enumerar las dificultades enfrentadas por el equipo de enfermería. Método: Se trata de un estudio retrospectivo, teniendo como fuente de información los prontuarios y los libros de registros de la RPA de cinco años (de julio de 2012 a julio de 2017), en un hospital público de Rio Grande do Sul. Resultados: Durante el período estudiado, 30 pacientes intensivos fallecieron en la RPA, siendo la mayor parte del sexo masculino, con edad promedio de 50,97 años, que permanecieron en el lecho, en promedio, por 14,8 horas, pertenecientes a la especialidad de neurocirugía, siendo la causa de óbito más frecuente el paro cardiorrespiratorio. Conclusión: La admisión de pacientes intensivos en la RPA requiere la adecuación de la unidad en su estructura física y operacional, con un equipo adecuado en número y capacitación técnica para garantizar una asistencia segura y humanizada a los pacientes intensivos, así como a los demás pacientes en pos-operatorio.

Palabras claves: Sala de recuperación. Periodo de recuperación de la anestesia. Enfermería posanestésica. Enfermería perioperatoria. Cuidados críticos.

'Enfermeira; especialista em Enfermagem de Urgência e Emergência Adulto e Pediátrica; enfermeira no Centro Cirúrgico do Hospital Cristo Redentor do Grupo Hospitalar Conceição - Porto Alegre (RS), Brasil. ¿Enfermeira; mestre em Ciência; professora do curso de especialização em Enfermagem em Centro Cirúrgico, Recuperação Anestésica e Centro de Material e Esterilização da Faculdade Israelita de Ciências da Saúde Albert Einstein - São Paulo (SP), Brasil.

*Autor correspondente: dulcijardim@hotmail.com

Recebido: 08/02/2018 - Aprovado: 29/05/2018

DOI: $10.5327 / Z 1414-4425201800030004$ 


\section{INTRODUÇÃO}

A morte é considerada um fato inevitável para todos, fazendo parte do ciclo natural da vida, mas os profissionais da enfermagem geralmente não estão adequadamente preparados para lidar com ela, tendo como base sua preparação acadêmica para o cuidado com a vida ${ }^{1-3}$.

Há, porém, setores no ambiente hospitalar onde os profissionais estão mais habituados a lidar como a morte, como é o caso da unidade de terapia intensiva (UTI), que é indicada para pessoas em estado de saúde crítico, dependentes de recursos tecnológicos para manutenção da vida e, em muitos casos, pacientes sem possibilidades terapêuticas ${ }^{1,3,4}$.

Sabe-se, porém, que atualmente tem havido um crescente aumento na demanda de pacientes críticos, inversamente proporcional ao aumento no número de leitos de UTI, o que tem obrigado as instituições a realizarem a assistência do paciente intensivo em outros setores enquanto aguardase a liberação de um leito na UTI.

Nesse sentido, a recuperação pós-anestésica (RPA) tem se tornado uma alternativa cada vez mais presente para admitir e assistir pacientes cirúrgicos críticos, devido à indisponibilidade de leitos na $\mathrm{UTI}^{5-7}$. Esse tipo de admissão não reflete o caráter principal desse setor, reconhecido como unidade de transição entre o despertar anestésico e a recuperação dos parâmetros vitais do paciente, visando sua transferência à unidade de internação ou à alta hospitalar ${ }^{8}$.

Cotidianamente, os cuidados prestados na RPA diferem muito daqueles da UTI, em razão da alta rotatividade e da necessidade de agilidade nas tomadas de decisões para atendimento das complicações pós-operatórias ${ }^{9}$, mas a unidade pode assegurar assistência de qualidade ao paciente intensivo, desde que sejam realizadas as adequações necessárias em relação à quantidade e ao preparo da equipe assistencial, de materiais e equipamentos 5 .

$O$ contexto da assistência ao paciente intensivo envolve a possibilidade de complicações graves e, por vezes, fatais. O óbito não configura um evento comum para a assistência pós -operatória oferecida na RPA, logo, sua ocorrência torna-se uma experiência descontextualizada e traz algumas dificuldades para a equipe, uma vez que requer manejo especial da mesma em relação à morte do paciente, bem como manejo em relação aos demais pacientes em pós-operatório imediato (POI), que já podem estar em estado de consciência.

Devido à escassez de produção científica relacionada à ocorrência de óbito na RPA, ressalta-se a relevância deste estudo, no sentido de colaborar com a reflexão e a elaboração de medidas utilizadas no preparo estrutural e de pessoal dessa unidade, em instituições que estejam vivenciando tal situação.

\section{OBJETIVOS}

- Identificar e caracterizar o perfil de pacientes intensivos que evoluíram a óbito durante sua permanência na RPA;

- Elencar as dificuldades enfrentadas pela equipe de enfermagem frente à situação de morte do paciente intensivo na RPA.

\section{MÉTODO}

Foi realizado um estudo retrospectivo, com coleta de dados realizada em dezembro de 2017, considerando-se como fonte de informação primária os dados fornecidos pelos livros de registros de admissões de pacientes na RPA dos últimos cinco anos (de julho de 2012 a julho de 2017). Desses registros, foram levantados os dados de todos os pacientes intensivos que evoluíram a óbito na RPA no período, no que se refere à caracterização do seu perfil, incluindo: sexo, idade, especialidade cirúrgica e tempo de permanência na unidade, somando-se a causa do óbito encontrada no prontuário dos pacientes.

A pesquisa foi realizada em um hospital público de grande porte, com 264 leitos, referência para atendimento de pacientes politraumatizados no Rio Grande do Sul. Possui seis salas operatórias $(\mathrm{SO})$ no centro cirúrgico (CC) central e uma SO no CC ambulatorial, onde são realizadas, em média, 525 cirurgias por mês nas especialidades de neurocirurgia, cirurgia geral, ortopedia, plástica, vascular e bucomaxilo. A RPA possui 12 leitos ativos e atende pacientes não críticos em POI, bem como pacientes intensivos que aguardam liberação de um leito na UTI.

Os dados da pesquisa foram organizados em planilha Excel, analisados por meio de estatística descritiva e do cálculo de medidas resumo, com apresentação dos resultados por meio de tabelas, gráficos e quadro ${ }^{10}$.

Esta pesquisa foi aprovada pelo Comitê de Ética em Pesquisa da instituição sede do estudo, via Plataforma Brasil, sob número CAAE 78636917.8.0000.553, segundo recomendações da Resolução n ${ }^{\circ}$ 466 / 2012, do Conselho Nacional de Saúde, que versa sobre pesquisas envolvendo seres humanos.

\section{RESULTADOS}

No período do estudo foram admitidos na RPA 717 pacientes intensivos, que deveriam ter sido encaminhados para a UTI, 
mas que, por indisponibilidade de leitos, foram admitidos na RPA. Desse grupo, 30 pacientes foram a óbito na RPA antes que um leito na UTI fosse disponibilizado. A distribuição anual dos óbitos dos pacientes na RPA está apresentada na Figura 1, onde se pode verificar que a porcentagem de óbitos decresce ao longo do tempo.

A idade dos pacientes variou entre 16 e 83 anos, com média de 50,97 anos e desvio padrão de 18,41 anos. Entre os 30 pacientes, $21(70,0 \%)$ eram do sexo masculino.

O tempo de permanência dos pacientes intensivos na RPA variou entre 25 minutos e 117 horas. Na Tabela 1 e na Figura 1, percebe-se que nos anos 2013, 2015 e 2016 houve pacientes com tempos de internação muito altos $(86,117$ e 37 horas, respectivamente). Excetuando esses pacientes, a média do tempo de internação dos pacientes não se alterou ao longo dos anos.

Em relação às especialidades cirúrgicas responsáveis pelos pacientes intensivos que evoluíram a óbito na RPA, a neurocirurgia foi a mais representativa (13 pacientes; $43,3 \%$ ), conforme mostra a Tabela 2 .

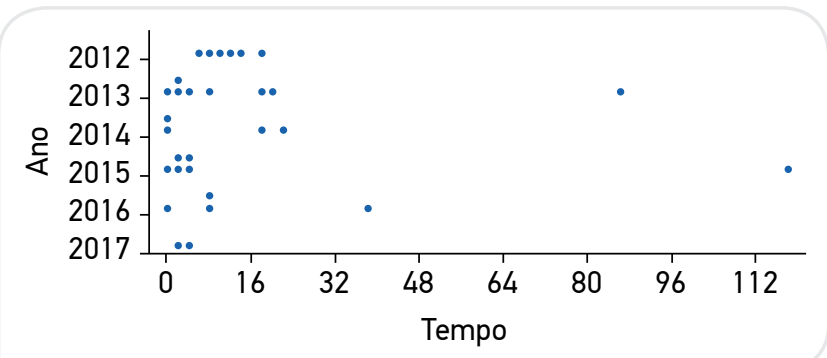

Figura 1. Distribuição do tempo de internação de pacientes intensivos que evoluíram a óbito em função dos anos.
As causas de óbito mais frequentes nas especialidades cirúrgicas, segundo dados dos prontuários dos pacientes, foram: hemorragia cerebral $(53,8 \%)$, morte encefálica $(30,7 \%)$ e parada cardiorrespiratória (PCR) $(30,7 \%)$ na neurocirurgia; PCR $(70,0 \%)$ e choque hipovolêmico $(30,0 \%)$ na cirurgia geral; e PCR $(100,0 \%)$ nas cirurgias ortopédica e vascular. Dessa forma, a PCR foi a principal causa de óbito, mas em alguns casos ela foi precedida de outra causa, a exemplo de choque hipovolêmico ou choque hemorrágico, sendo ambas as causas descritas na Figura 2.

Em relação ao tempo de permanência dos pacientes na RPA, segundo a sua especialidade, a neurocirurgia mostrou-se como a mais representativa (média $=85,5 \mathrm{~h}$ ), seguida das cirurgias vascular (média $=13,4 \mathrm{~h}$ ), ortopédica (média $=6,8 \mathrm{~h}$ ) e geral (média $=6,3 \mathrm{~h}$ ).

No processo de atendimento ao paciente intensivo em uma intercorrência grave, como a PCR, e em procedimentos de reanimação, a equipe de enfermagem da RPA se depara com algumas dificuldades de ordem assistencial e estrutural, as quais estão apresentadas no Quadro 1.

Tabela 2. Caracterização dos pacientes intensivos que evoluíram a óbito na recuperação pós-anestésica, segundo a especialidade médica.

\begin{tabular}{|l|c|c|}
\hline Especialidade & $\mathbf{n}$ & $\%$ \\
\hline Neurocirurgia & 13 & 43,3 \\
\hline Cirurgia geral & 10 & 33,3 \\
\hline Cirurgia ortopédica & 5 & 16,7 \\
\hline Cirurgia vascular & 2 & 6,7 \\
\hline Total & 30 & 100,0 \\
\hline
\end{tabular}

Tabela 1. Pacientes admitidos na recuperação pós-anestésica, pacientes intensivos e casos de óbito por ano, média e erro padrão do tempo de permanência na recuperação pós-anestésica.

\begin{tabular}{|c|c|c|c|c|c|c|}
\hline \multirow[t]{2}{*}{ Ano } & \multirow{2}{*}{$\begin{array}{c}\text { Pacientes } \\
\text { admitidos } \\
\text { na RPA }\end{array}$} & \multirow{2}{*}{$\begin{array}{c}\text { Total de } \\
\text { pacientes } \\
\text { intensivos }\end{array}$} & \multicolumn{2}{|c|}{$\begin{array}{l}\text { Total de pacientes intensivos } \\
\text { que foram a óbito }\end{array}$} & \multirow{2}{*}{$\begin{array}{l}\text { Média do tempo } \\
\text { de permanência } \\
\text { (horas) }\end{array}$} & \multirow{2}{*}{$\begin{array}{l}\text { Erro padrão do tempo } \\
\text { de permanência } \\
\text { (horas) }\end{array}$} \\
\hline & & & $n$ & $\%$ & & \\
\hline 2012 & 2.322 & 58 & 6 & 10,3 & 11,72 & 1,86 \\
\hline 2013 & 4.642 & 148 & 8 & 5,4 & 17,80 & 10,20 \\
\hline 2014 & 4.144 & 89 & 4 & 4,4 & 10,69 & 5,78 \\
\hline 2015 & 4.585 & 169 & 6 & 3,5 & 21,40 & 19,10 \\
\hline 2016 & 4.398 & 177 & 4 & 2,2 & 13,75 & 8,27 \\
\hline 2017 & 2.242 & 76 & 2 & 2,6 & 3,17 & 1,41 \\
\hline Total & 22.333 & 717 & 30 & 4,1 & 14,84 & 4,66 \\
\hline
\end{tabular}

RPA: recuperação pós-anestésica. 


\section{DISCUSSÃO}

O atendimento a complicações graves e fatais não faz parte do contexto original da RPA, mas tem se tornado cada vez mais comum, devido à necessidade da utilização do setor como leito de retaguarda da UTI. A ocorrência do óbito na RPA, embora seja uma experiência descontextualizada, precisa ser atendida e, para tanto, vencidas as dificuldades que com ela surgem.

Neste estudo, dos 30 pacientes que foram a óbito, a maioria era do sexo masculino, na faixa etária adulta, corroborando achados da literatura em relação ao sexo e à idade de pacientes assistidos na RPA 9 .

A média do tempo de permanência do paciente em POI na RPA é de 111,2 minutos, ${ }^{9}$ o que retrata a alta rotatividade de leitos, característica da unidade. O tempo de permanência dos pacientes intensivos apresentou grande variação, a qual aparece, também, em outro estudo com variação ainda maior, entre 3 e 384 horas 5 . O tempo médio de permanência de 14,8 horas neste estudo foi menor do que em um estudo realizado em 2015, no qual se constatou média de 41,4 horas 5 . Quando se compara a categoria de cuidados com as horas de permanência, observa-se que os pacientes com cuidados intensivos têm mediana de horas de permanência significativamente maior do que as demais categorias ${ }^{11}$.

O menor tempo de espera do paciente intensivo por um leito na UTI foi de apenas 25 minutos, ou seja, o tempo gasto apenas com a admissão do paciente na RPA, passagem de plantão e adequação do leito, materiais e equipamentos

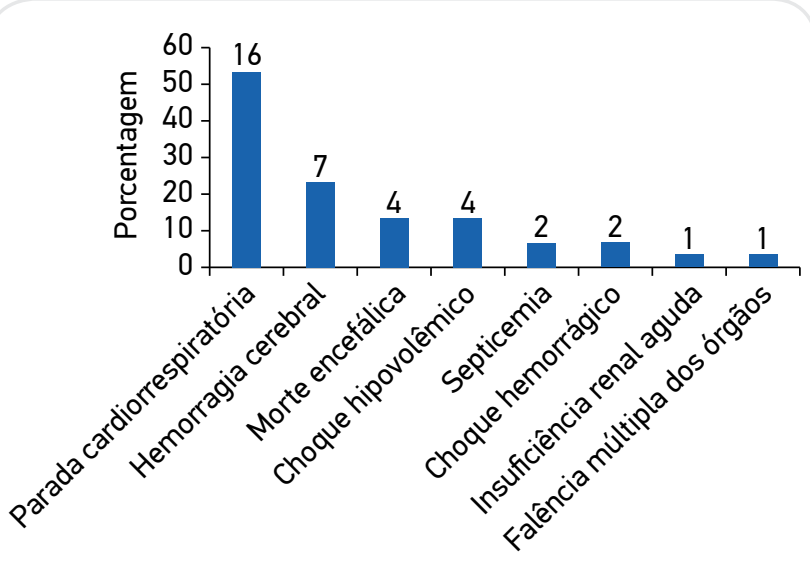

Causa de óbito

Cada porcentagem foi calculada sobre 30 pacientes.

Figura 2. Causas de óbitos dos pacientes intensivos na recuperação pós-anestésica.
Quadro 1. Dificuldades da equipe de enfermagem em relação à ocorrência do óbito na recuperação pós-anestésica.

Dificuldades assistenciais e operacionais

Atendimento médico: não há presença de plantonista médico na unidade aos finais de semana e em períodos noturnos. Em situações de emergência nesses períodos, a enfermeira envia contato, por meio de BIP, para a especialidade responsável pelo paciente, solicitando sua presença no setor e, em casos extremos, solicita a presença do plantonista da UTI. Em ambos os casos, há demora para a chegada de um médico na RPA, gerando estresse na equipe de enfermagem e riscos para o paciente.

- Assistência de enfermagem: não há presença exclusiva do enfermeiro na RPA nos plantões noturnos (a partir da $1 \mathrm{~h}$ da manhã) e aos finais de semana, períodos em que apenas um enfermeiro realiza a supervisão de todo o BC. Há, ainda, a necessidade de adequação da escala de técnicos, em virtude da admissão de pacientes intensivos na RPA, a fim de garantir o dimensionamento adequado dos profissionais e a consequente qualidade da assistência.

- Cuidados com o corpo: após a constatação do óbito, a enfermagem deve realizar o preparo do corpo, sua identificação e transferência para local adequado, além do preenchimento de impressos específicos, segundo a rotina da instituição, bem como a localização da família para comunicação do ocorrido pela equipe responsável pelo paciente. Esses procedimentos demandam tempo do enfermeiro, que deixa de assistir os pacientes na RPA ou em todo o BC.

- Reorganização do ambiente: após a saída do corpo, é necessária a realização de limpeza dos equipamentos utilizados pelo paciente, bem como a higienização do box pela equipe de higiene, seguida da reorganização do leito para nova admissão. 0 tempo despendido nesse procedimento impacta a rotatividade dos leitos na RPA.

\section{Dificuldades relacionadas à}

infraestrutura e aos serviços de apoio

- Espaço físico: o espaço físico na RPA é insuficiente para atendimento aos pacientes intensivos. Requer espaço adicional para o carrinho de atendimento à PCR e para os profissionais envolvidos no atendimento em situações de emergência. A separação entre os leitos é feita apenas com uma cortina, cuja parte frontal do leito fica aberta, permitindo que os pacientes em $\mathrm{POI}$, muitas vezes acordados e conscientes, presenciem todo o atendimento e o óbito.

Fornecimento de medicamentos: para o fornecimento de medicamentos que não estão no carro de atendimento à PCR, como os fármacos controlados, há necessidade da presença do enfermeiro para retirá-los. Isso ocasiona a ausência do mesmo da unidade, prejudicando a qualidade da assistência.

- Exames: ocorre demora para realização de exames e entrega dos resultados dos mesmos. No caso de gasometria, a amostra é coletada pela enfermeira e processada em equipamento localizado na UTI ou no laboratório central, em outra unidade do complexo hospitalar, a depender do dia/horário do evento. Caso seja preciso utilizar o equipamento de raio $X$, é feito contato telefônico com o setor para o colaborador da radiologia se dirigir à RPA, onde é utilizado o aparelho do CC, com saída e retorno do profissional para revelação e entrega do exame depois de pronto.

UTI: unidade de terapia intensiva; RPA: recuperação pós-anestésica; BC: bloco cirúrgico; PCR: parada cardiorrespiratória; POI: pós-operatório imediato; CC: centro cirúrgico. 
necessários para a sua assistência. Nesse caso, o paciente poderia sair da SO e ir direto para a UTI. Portanto, a comunicação entre o CC e a UTI precisa ser bem alinhada para evitar desgaste desnecessário da equipe da RPA com admissão e transferência imediata do paciente.

Em outro extremo, o maior tempo de permanência na RPA foi de 117 horas, o que resulta em bloqueio do leito por mais de 4 dias, somado a uma assistência intensiva. Para a equipe, é frustrante a ocorrência do óbito após tanto tempo de cuidados, afinal a morte é geradora de sentimentos como dor, tristeza, sofrimento, medo, impotência e insucesso, podendo ser resultado de uma formação acadêmica voltada para o tratamento e a cura das doenças, o que leva os profissionais a pensarem ser possível curar sempre ${ }^{2}$. Portanto, é necessário interpretar a morte como terapêutica, um desfecho necessário para aliviar o sofrimento de um indivíduo que não reúne chances de sobrevida ${ }^{1}$.

A neurocirurgia foi responsável pela maior parte dos pacientes deste estudo, reflexo da essência da instituição sede da pesquisa, que se apresenta como referência para pacientes politraumatizados.

A principal causa de óbito dos pacientes deste estudo foi a PCR, considerada a forma mais comum de limitação da vida em pacientes críticos e terminais, a qual resulta na cessação súbita e inesperada da atividade mecânica ventricular. Essa atividade é uma intercorrência grave e o modo mais rápido de revertê-la é por meio da reanimação cardiopulmonar (RCP $)^{1}$.

Sabe-se que o cenário de ocorrência da PCR pode influenciar na sobrevida dos pacientes, pois uma vez que ocorra no ambiente hospitalar, espera-se que o início da RCP seja mais rápido e que o paciente apresente recuperação da circulação espontânea ${ }^{12}$. Neste estudo, porém, a demora do atendimento médico foi apontada como uma dificuldade em horários noturnos e em finais de semana, quando não há intensivista de plantão na RPA. Nesse sentido, ressalta-se a importância da correção desse cenário pela instituição, que necessita se adequar à demanda da RPA durante as 24 horas de assistência.

Outro fator importante para o sucesso da RCP é a capacitação da equipe que a executa ${ }^{12}$. Dessa forma, faz-se preciso a realização de treinamentos e atualizações com a equipe de enfermagem da RPA para um eficaz atendimento diante de uma PCR e em outros cuidados intensivos necessários para o atendimento do paciente de UTI. Na literatura, a enfermagem que atua na RPA aponta como principais dificuldades da equipe, ao prestar assistência a pacientes intensivos, o manuseio da ventilação mecânica, a administração de fármacos por bomba de infusão, a realização de banho no leito e a troca constante de fraldas ${ }^{5,7}$.
Além da capacitação, há necessidade de adequação do número de colaboradores de enfermagem na RPA, outra dificuldade apontada neste estudo. A Associação Brasileira de Enfermeiros em Centro Cirúrgico, Recuperação Anestésica e Centro de Material e Esterilização (SOBECC) ${ }^{13}$ recomenda a proporção de um enfermeiro para três ou quatro pacientes que dependem de respirador e um técnico de enfermagem para cada três pacientes.

Conforme apresentado anteriormente, a presença de enfermeiro exclusivo para a RPA não ocorre nos plantões noturnos e aos finais de semana, o que precisa ser corrigido pela instituição sede do estudo, além da adequação da escala de técnicos, em virtude da presença e da quantidade de pacientes intensivos em cada plantão. Essa adequação exigirá esforço do enfermeiro coordenador do setor, devido à imprevisibilidade de admissões de pacientes intensivos.

Somam-se ainda às dificuldades assistenciais, os cuidados com o corpo após a morte, que, ainda que sejam considerados simples, trazem uma forte carga emocional aos colaboradores e descontextualizam o tipo de assistência prestada no setor. Ressalta-se que esse cuidado deve ser realizado com técnica, mas, principalmente, com respeito e consideração, pois cuidar do paciente independe do seu estado vital ${ }^{2}$.

Quanto às dificuldades relacionadas à limitação do espaço físico da RPA e ao acesso a materiais, equipamentos e exames, essas são sentidas em outras instituições descritas na literatura $^{5,7}$, exigindo, por parte delas, readequação do ambiente, com espaço suficiente entre os leitos para uma assistência segura e privativa, protegendo os demais pacientes em POI de cenas constrangedoras e/ ou traumatizantes, além de reorientação em procedimentos internos, a fim de colaborar com o bom atendimento de pacientes críticos.

Da mesma forma, os processos administrativos, citados como itens de dificuldade para os colaboradores de enfermagem deste estudo e de outros ${ }^{5,7}$, precisam ser simplificados, de forma a demandar menos tempo e esforço de uma equipe assistencial já sobrecarregada. É salutar a presença de um profissional administrativo na RPA, com experiência em UTI, para agilizar o preenchimento de impressos e a organização dos prontuários desses pacientes.

É necessário, ainda, refletir sobre a ocorrência do óbito na RPA, sob o ponto de vista psicossocial do colaborador de enfermagem, que deve olhar para a morte com uma tranquilidade pelo menos relativa, uma vez que ela faz parte da existência humana e precisa ser compreendida como parte do ciclo de vida, e oferecer ao paciente uma boa morte, entendida como aquela em que a pessoa está livre de dor ${ }^{4}$.

Sabe-se que há grande preocupação, por parte da equipe de enfermagem, em demonstrar apoio, atenção e afeto também 
à família do paciente grave, possibilitando trocas intersubjetivas nos últimos momentos ${ }^{4}$. Na RPA, a visita de familiares é um evento que não ocorre em sua condição normal de assistência, sendo feita uma adequação na unidade em questão, de horário pré-estabelecido uma vez ao dia, em virtude da presença de pacientes intensivos, o que não possibilita troca significativa entre a equipe e a família do paciente.

Dessa maneira, torna-se importante valorizar o acolhimento de familiares, com flexibilização de normas e rotinas hospitalares relacionadas às visitas, permitindo maior interação entre a família e seu membro internado e respeito aos vínculos afetivos, bem como torna-se necessária a capacitação emocional da equipe multiprofissional para lidar com o sofrimento de ambos, promovendo, assim, conforto ${ }^{3,4}$.

Nesse sentido, é necessário que a enfermagem entenda a morte como parte do ciclo vital e, assim, seja repensado o cuidar/ cuidado como a essência da enfermagem, discutindo a temática da morte, tanto no meio acadêmico quanto na prática diária ${ }^{3}$.

As limitações deste estudo estão relacionadas à sua realização em única instituição de caráter público, e com um número reduzido de pacientes, mas que reflete o fato do óbito ser um evento não pertinente à RPA, sendo, portanto, salutar compartilhar essa vivência com outros profissionais que começam a conviver com o óbito em sua assistência pós-operatória.

\section{CONCLUSÃO}

Neste estudo, constatou-se que, entre julho de 2012 e julho de 2017, 30 pacientes intensivos foram a óbito na RPA, enquanto aguardavam a liberação de um leito da UTI, em um hospital da rede pública do sul do país. A maior parte era do sexo masculino, com idade média de 50,97 anos. Os pacientes permaneceram no leito, em média, por 14,8 horas, a maioria pertencente à especialidade de neurocirurgia, sendo a causa de óbito mais frequente a PCR.

Em virtude da necessidade de admissão de pacientes de UTI na RPA, é imprescindível a adequação da unidade em sua estrutura física, com espaço e fornecimento de insumos e exames adequados, além de equipe médica e de enfermagem em quantidade e capacitação adequadas, nas 24 horas, a fim de garantir uma assistência de qualidade que assegure a humanização do cuidado e a segurança do paciente intensivo, bem como dos demais pacientes que se encontram em POI na RPA.

\section{REFERÊNCIAS}

1. Beraldo LM, Almeida DV, Bocchi SCM. Da frustração ao enfrentamento do cuidado para a morte por técnicos de enfermagem. Rev Bras Enferm. 2015;68(6):1013-9. http://dx.doi. org/10.1590/0034-7167.2015680603i

2. Mota MS, Gomes GC, Coelho MF, Lunardi Filho WD, Sousa LD. Reações e sentimentos de profissionais da enfermagem frente à morte dos pacientes sob seus cuidados. Rev Gaúcha Enferm. 2011;32(1):129-35. http://dx.doi.org/10.1590/S1983-14472011000100017

3. Silva RS, Campos AER, Pereira A. Cuidando do paciente no processo de morte na Unidade de Terapia Intensiva. Rev Esc Enferm USP. $2011 ; 45(3): 738-44$. http://dx.doi.org/10.1590/ S0080-62342011000300027

4. Silva RS, Pereira A, Mussi FC. Conforto para uma boa morte: perspectiva de uma equipe de enfermagem intensivista. Esc Anna Nery. 2015;19(1):40-6. http://dx.doi.org/10.5935/1414-8145.20150006

5. Nascimento P, Jardim DP. Pacientes de cuidados intensivos em leito de retaguarda na recuperação pós-anestésica. Rev SOBECC. 2015;20(1):38-44. http://dx.doi.org/10.5327/ Z1414-4425201500010005

6. Saraiva EL, Sousa CS. Pacientes críticos na unidade de recuperação pós-anestésica: revisão integrativa. Rev SOBECC. 2015;20(2):104-12. http://dx.doi.org/10.5327/Z1414-4425201500020006
7. Souza TFM, Jardim DP. Assistência de enfermagemem leitos de retaguarda na recuperação pós-anestésica. Revista SOBECC. 2011;16(2):43-9.

8. Lima LB, Rabelo ER. Carga de trabalho de enfermagem em unidade de recuperação pós-anestésica. Acta Paul Enferm. 2013;26(2):116-22. http://dx.doi.org/10.1590/S0103-21002013000200003

9. Popov DC, Peniche AC. Nurse interventions and the complications in the post-anesthesia recovery room. RevEsc Enferm USP. 2009;43(4):946-54. http://dx.doi.org/10.1590/S0080-62342009000400030

10. Bussab WO, Morettin PA. Estatística básica. $8^{a}$ ed. São Paulo: Saraiva; 2013.

11. Lima LB, Borges D, Costa S, Rabelo ER. Classification of patients according to the degree of dependence on nursing care and illness severity in a post-anesthesia care unit. Rev Latino-Am Enferm. 2010;18(5):881-7. http://dx.doi.org/10.1590/S0104-11692010000500007

12. Silva RM, Silva BA, Silva FJ, Amaral CF. Ressuscitação cardiopulmonar de adultos com parada cardíaca intra-hospitalar utilizando o estilo Utstein. Rev Bras Ter Intensiva. 2016;28(4):427-35. http://dx.doi. org/10.5935/0103-507x.20160076

13. Associação Brasileira de Enfermeiros de Centro Cirúrgico, Recuperação Anestésica e Centro de Material e Esterilização. Diretrizes de práticas em enfermagem cirúrgica e processamento de produtos para a saúde. 7a ed. São Paulo: SOBECC / Barueri: Manole; 2017. 